\title{
MONOSODIUM GLUTAMATE EXPOSURE AT EARLY DEVELOPMENTAL STAGE INCREASES APOPTOSIS AND STEREOTYPIC BEHAVIOR RISKS ON ZEBRAFISH (DANIO RERIO) LARVAE
}

\author{
Nia Kurnianingsih ${ }^{1 \# *}$, Juliyatin Putri Utami ${ }^{2 \#}$, Nurdiana $^{3}$, Diana Lyrawati ${ }^{4}$
}

\begin{abstract}
1Dept of Physiology, Fac. of Medicine, Brawijaya Univ., Malang 65145, Indonesia 2Master Program on Biomedical Science, Faculty of Medicine, Brawijaya Univ., Malang 65145, Indonesia ${ }^{3}$ Dep.t of Pharmacology, Fac. of Medicine, Brawijaya Univ., Malang 65145, Indonesia ${ }^{4}$ Dept of Pharmacy, Fac. of Medicine, Brawijaya Univ., Malang 65145, Indonesia
\end{abstract}

Submitted: $12-05-2016$

Revised: $16-07-2016$

Accepted: $10-08-2016$

*Corresponding author Nia Kurnianingsih

Email:

nia_fkub@ub.ac.id.

\begin{abstract}
Excessive glutamate may give neurotoxic effects and contribute to Autism spectrum disorder(ASD). In this study, we investigated prolonged exposure effects of $10 \mu \mathrm{g} / \mathrm{mL}$ Monosodium Glutamate (MSG) on intracellular calcium level, bax, $b c l-2$, ratio of $b a x / b c l-2$ genes expression, caspase-3, apoptosis of brain cells and stereotypic behavior of Zebrafish (Danio rerio) larvae at early developmental stages. Genes expression were determined by real time PCR, caspase-3 using ELISA, intracellular $\mathrm{Ca}^{2+}$ and apoptotic cells of brain using confocal microscopy, locomotor activity by using crossing lines assay whereas stereotypic behavior by circle swimming. The results indicated that MSG exposure increased brain bax and $\mathrm{bcl}-2$; and caspase-3; intracellular $\mathrm{Ca}^{2+}$; and apoptosis; stereotypic behavior; and decreased locomotor activity. Termination of MSG treatments resulted in recovery of $b a x, b c l-2$, caspase-3 basal levels and stereotypic behavior. In conclusion, MSG exposure at early embryonic stage increased brain cell damage and risk of behavior changes.
\end{abstract}

Key words: Monosodium glutamate, early embryo, duration, apoptosis, Behavior.

\section{INTRODUCTION}

Autism spectrum disorder (ASD) is a developmental disorder in children, with increasing estimated prevalence up to 1 in every 68 children in United States (Baio, 2014). Stereotypic behavior is one of the diagnosis criteria for ASD based on the Diagnostic and Statistical Manual of Mental Disorder V (DSM $\mathrm{V)}$ of the American Psychiatric Association (APA, 2013). ASD is the result of many genetic (Roberts et al., 2014), environmental (Jones et al., 2013) or both factors (Fatemi et al., 2012).

Among many of suspected ASD etiologies is the involvement of neurotoxin substances affecting in either pre-natal and/or post-natal development. Glutamate, an amino acid and main excitatory neurotransmitter in central nervous system, is a neurotoxicant when accumulated excessively (Mattson $e t$ al., 2008). Monosodium glutamate (MSG), commonly consumed as a food additive enhancing savory and delicious taste, is one of the source of glutamate. There are serious neurotoxic effects from MSG when administered to animals in very large doses (Gonzales-Burgos et al., 2001). Extracellular glutamate activates NMDA receptors ( $\mathrm{N}$-methyl-D-Aspartate) which then trigger the build up of excessive $\mathrm{Ca}^{2+}$ in the cell (Rizzuto et al., 2003). High amount of intracellular $\mathrm{Ca}^{2+}$ leads to increased permeability of the mitochondrial membrane, followed by opening of its pores and activates caspase cascade resulted in apoptosis (Siniscalco, et al., 2012). Apoptosis in brain is associated with ASD as reported in post-mortem studies in which an increase of p53 transcription factor and drastic reduction of Bcl-2 anti-apoptotic protein were detected in the frontal cortex and cerebellum areas (Fatemi et al., 2001). Bax, a pro-apoptotic gene may also have an influence although its studies in ASD are still limited.

Most of the studies emphasized on acute high doses of MSG effects in brain and conducted during post-natal development (Geha et al, 2000). Limited data with conflicting findings have been reported on effects of prolonged exposure of MSG, during fetal or early embryonic development (Husarova et al., 
2013). Some human studies concluded that glutamate did not pass placental barrier into fetal circulation (Beyreuther et al., 2007; Walker et al., 2000). In animal studies, others showed the opposites, oral MSG $2 \mathrm{mg} / \mathrm{g}$ given immediately post-natal for 10 days (Ali et al., 2000) and MSG 2g/kg body weight at 17 days of pregnancy resulted in decreased learning performance and hippocampal neuronal degeneration in the neonatal mice (Zhang et al., 2010).

Zebrafish is a promising animal experimental model for study of excitotoxins, for instance MSG (Mahaliyana et al., 2016). Almost all of Zebrafish genome has complete sequence and has ortholog to various disease gene in human, including to explore genetic basis of autism. The rapid embryo development, the abundance of egg production, the transparency of embryo, and the external development ease researcher to observe and roll the study in a short period (Banerjee et al., 2014). So far, the study of the effects of MSG exposure on Zebrafish was only performed to evaluate the effects of different concentration (Mahaliyana et al., 2016; Abdelkader et al., 2012). The study that focus on the effects of low dose MSG exposure with different duration on Zebrafish embryo stage development has not yet been conducted before.

Thus, the aim of our present study is to clarify the behavioral effect of long term MSG administration on zebrafish embryos exposed at the first developmental stages ( $2 \mathrm{~h}$ postfertilization) with different duration i.e. 24, 48, and $72 \mathrm{~h}$. We focused on mitochondrialdependent apoptotic pathway and stereotyped behavior effects of the larvae.

\section{MATERIALS AND METHODS} Zebrafish maintenance

Adult wild type zebrafish both sexes were obtained from local fish supplier and species identification was validated by experts from Indonesian Institute of Sciences. Zebrafish were kept in glass aquaria with $50 \mathrm{~L}$ capacities, at $28.5^{\circ} \mathrm{C}$, with $14: 10 \mathrm{~h}$ lightdark photocycle (Westerfield et al., 2000). Fish were fed twice daily (Tetramin Tropical Fish Flakes, USA). Eggs were collected in the beginning of light period (Tiedeken et al., 2005).
All procedures were approved by Health Research Ethics Committee of Faculty of Medicine, Brawijaya University (Registration 608/EC/ KEPK S2/11/2014 and 045/EC/KEPK/ 01/2015).

\section{MSG preparation and exposure}

Monosodium glutamate, $\mathrm{C}_{5} \mathrm{H}_{8} \mathrm{NNaO}_{4}$ $\mathrm{H}_{2} \mathrm{O}$ (Sigma-Aldrich, CAS 142-47-2), was prepared as a $10 \mu \mathrm{g} / \mathrm{mL}$ solution in distilled water (Abdelkader et al., 2012). Fertilized eggs were washed twice and assigned into 4 groups i.e. (i) control (distilled water) and MSG treatments for (ii) 24 ; (iii) 48 ; and (iv) $72 \mathrm{~h}$ started at 32-64 cell stage (approximately at $2 \mathrm{hpf}$ ). Thirty eggs were placed into each well of 6-well plate filled with $8 \mathrm{~mL}$ of $10 \mu \mathrm{g} / \mathrm{mL} \mathrm{MSG}$ solution or distilled water, in three replicates, to give a total of 90 eggs per group of treatment. Thirty percent of the solution was replaced daily with fresh one. Embryos were kept in incubator, at $28.5^{\circ} \mathrm{C}$, with $14: 10 \mathrm{~h}$ light-dark photocycle (Westerfield et al., 2000).

\section{Embryo Monitoring Assay}

Embryos were morphologically evaluated for body defects using stereo microscope (SZPT, Olympus, Japan). The body length was measured as the distance of the head to tail bud. Survival and hatching rates were monitored following exposure to MSG everyday (at 24, 48 and 72hpf). Embryos, 30 from each treatment, were checked for heartbeat at $72 \mathrm{hpf}$ post-treatment, also prior processing for molecular and behavior assays to ensure embryos were alive (Pramulawati et al., 2014).

\section{Intracellular $\mathrm{Ca}^{2+}$ imaging}

Intracellular $\mathrm{Ca}^{2+}$ level was determined in $72 \mathrm{hpf}$ embryos, post-treatment, incubated in $60 \mu \mathrm{g} / \mathrm{mL}$ Fura-2AM (Sigma Aldrich, Cat\# 47989) containing $2.5 \%$ DMSO in embryo medium for $30 \mathrm{~min}$ at room temperature (Muntean et al., 2010). After washing embryos were mounted in 3\% methylcellulose (Sigma Aldrich) and positioned for confocal laser scanning microscopic imaging (Olympus IX81 and FluoViewFV1000). In depth pictures were captured by scanning at 100 and 200x magnifications (approximately 30 focal planes/embryo). 
Nia Kurnianingsih

Table I. Gene specific primers used for quantitative real time PCR

\begin{tabular}{llll}
\hline Gene & Forward primers (5'-3') & Reverse primers (5'-3') & Accession number \\
\hline Bcl-2 & TTGTGGAGAAATAC & GAGTCTCTCTGCTGA & BC133848 \\
& CTCAAGCAT & CCGTACAT & (Abdelkader et al., 2013) \\
Bax & GAGCTGCACTTCTC & CTGGTTGAAATAGCC & BC055592 \\
& AACAACT & TTGATGAC & (Abdelkader et al., 2013) \\
\multirow{2}{*}{ B-actin } & CGAGCAGGAGATG & CAACGGAAACGCTCA & AF057040 \\
& GGAACC & TTGC & (McCurley et al., 2008) \\
\hline
\end{tabular}

Fluorescence intensity was recorded at $340 / 380 \mathrm{~nm}$ extinction and 515nm emission fluorescent ratio, calibrated with $\left[\mathrm{Ca}^{2+}\right]$ values offline. Regions of interest were selected and analyzed using Fluoviewver $1.7 \mathrm{a}$ and Imagesoftwares compute

$\mathrm{d}$ for total of fluorescence intensity $=$ total pixel area $\times$ average pixel intensity of positive signals per $\mu \mathrm{m}$ in the brain.

\section{Apoptosis assay}

Brain cell apoptosis was identified with $5 \mu \mathrm{g} / \mathrm{mL}$ acridine orange $(\mathrm{AO})$ staining [acridinium chloride hemi-(zinc chloride), Sigma-Aldrich] for 60minutes (Parng et al., 2006). Four 72hpf embryos/group were observed in depth (approximately 50 optical slices/embryo) confocal imaging with acridine orange filter setting. Positive signals of apoptotic cells were defined by fluorescence intensity and size of particle exhibited a punctate AO staining pattern in the brain.

\section{RNA Extraction and real time PCR of $B C l-2$ and $B a x$}

Brain tissue from 6 larva from each group were collected using glass micro-capillaries at 7 days after fertilization (Vargas et al., 2011). Brain tissue was homogenized for RNA isolation according to TRI reagent ${ }^{\circledR}$ (SigmaAldrich). Isolated RNA was checked for quality (A260/280nm 1.8-2.2) and quantity (NanoDrop Spectrophotometer 1000A). Real time assays were performed according to i-Green ${ }^{\text {TMOne }}$ Step qRT-PCR Kit (Intron Biotechnology, Cat\# 25107) using a Light Cycler ${ }^{\circledR} 1.5$ Instrument (Roche Diagnostics, USA). PCR primers (Table I) were used and the thermal profile for real-time was $42^{\circ} \mathrm{C}$ for $15 \mathrm{~min} ; 95^{\circ} \mathrm{C}$ for $10 \mathrm{~min}$; followed by 35 cycles of $95^{\circ} \mathrm{C}$ for
$15 \mathrm{~s} ; 60^{\circ} \mathrm{C}$ for $60 \mathrm{~s}$; and $50^{\circ} \mathrm{C}$ for $60 \mathrm{~s}$. $\beta$-actin was used to normalize the results. Each mRNA level was expressed as a ratio to $\beta$-actin mRNA. Three replicates (pools of brain tissues) and three technical replicates of each RNA sample were performed. Relative mRNA expression for each gene was calculated as a fold change compared with the control group.

\section{Enzyme Linked Immunosorbent Assays (ELISA) of Caspase-3}

Brain tissues from 7 dpf zebrafish larva, visualized under stereomicroscope (Olympus SZX16), were collected using glass microcapillaries (Vargas et al., 2011) and used for protein isolation (RIPA-PIC, Thermo Scientific). Caspase-3 levels were analyzed by using ELISA(MyBioSource, Cat\# MBS012786). Six embryos were utilized/assay/group, repeated 3 times, totaling 18 embryos/group.

\section{Behavior assays}

Locomotor activities were tested on 24 larva/group aged $6 \mathrm{dpf}$ when spontaneous and reflective swimming competencies were mostly attained (Guo et al., 2004). Each well of a 12well plate, containing one larva/well, was gridded with horizontal and vertical lining crosses each other dividing each well into 4 compartments. Larvae video were recorded for $1 \mathrm{~min}$ twice and counted for total number passing the lines (Ingebretson et al., 2013).

Ten post-treatment larvae/group were analyzed for stereotypic behavior (Stewart et al., 2013; Stewart et al., 2011) on 3 and $7 \mathrm{dpf}$ and repeated thrice (total 30 larvae/group). Circle swimming was monitored on larvae, placed in $54 \mathrm{~mm}$ diameter Petri dish filled with water at $27^{\circ} \mathrm{C}$, following a touch of stimulus on their tail. 


\section{Statistical analysis}

Data, shown as mean \pm SEM, were screened for normality and homogeneity, and differences analyzed using ANOVA, KruskalWallis or Fisher-Exact (GraphPad Prism 5 software), with $\mathrm{p}<0.05$ considered as statistically significant.

\section{RESULTS AND DISCUSSION Morphological changes, heartbeat larvae and monitoring assays}

Inter-group differences in survival $(\sim 86 \% ; \mathrm{p}=0.8495)$ and hatching rate (all hatched) did not observed, however heartbeat rates of larvae exposed to MSG were higher than control group (Figure 1). Heartbeat rates of control group were $\sim 140 \mathrm{bpm}$, whereas in MSG groups $>150 \mathrm{bpm}(\mathrm{p}=0.0249)$. Morphologically, we found there were two abnormal embryos from $72 \mathrm{~h}$ MSG treated group, one with shorten body length and one with cardiac sac edema (Figure 1).

\section{Early exposure of MSG Increases Calcium; Bax; Bcl-2; caspase-3 levels and apoptosis of brain cells}

Following MSG treatment at early embryonic stage for 24,48 , and $72 \mathrm{~h}$, levels of calcium, bax, bcl-2, and caspase-3 increased significantly compared with that of control untreated group. Calcium increased with MSG exposure duration $(\mathrm{p}<0.0001)$. The relative mRNA expression of $B a x$ and $B c l-2$ were normalized against $\beta$-actin (housekeeping gene) and expressed as ratio to the control group (Figure 2-3). Compared with control group, $B a x ; B c l-2$; and the ratio between $B a x / B c l-2$ were higher in 48 and $72 \mathrm{~h}$ groups than control and 24h MSG incubation groups (two-way Anova $\mathrm{p}<0.0001$; Tukey Multiple Comparison for ratio of $\mathrm{Bax} / \mathrm{Bcl}-2 \quad 48 \mathrm{~h}$ vs control $\mathrm{p}=0.0170 ; \quad 72 \mathrm{~h}$ vs control $\mathrm{p}=0.0209)$. Caspase- 3 , on the other hand, sharply increased at $72 \mathrm{~h}$ incubation with MSG.

Brain apoptosis were higher in MSG treated groups than control group with ratio of apoptosis of MSG treated/control groups of total brain ranged 1.14-3.99 (One-way Anova $\mathrm{p}=0.046)$, whereas cerebellum region ranged 1.43-268.41 (Kruskal-Wallis $\mathrm{p}=0.0092$ ). Apoptosis was highest in group of early embryos treated with MSG for $72 \mathrm{~h}$, reaching on average for total area of brain 2.5 times and for cerebellum area alone 82 times higher than control group.

\section{MSG Increased Circle Swimming Events and Decreased Locomotor Activity}

Tactile sensibility which measured by circle swimming assay, was affected by MSG, detected immediately following exposure (3dpf embryos) in all treated groups (Fisher Exact one tailed $\mathrm{p}=0.039$; $\mathrm{OR}=28.11$ ). Interestingly, further observation on 7dpf larvae, the circle swimming deviation was not detected in any groups (Figure 3F). Early embryonic exposure of MSG starting at $1 \mathrm{dpf}$ for $24-72 \mathrm{~h}$ resulted in decreased locomotor activity (one-way Anova, $\mathrm{p}=0.0056$ ) observed in larvae 6dpf (Figure 3G).

Result of this study indicated that MSG exposure at a dose $10 \mu \mathrm{g} / \mathrm{mL}$ for 24,48 or $72 \mathrm{~h}$ during early embryonic development increased heart rates of the embryos and risk of heart and body defects. Those observations were not the main parameters in this study, yet indicated that $10 \mu \mathrm{g} / \mathrm{mL}$ MSG may increase risk of developmental defects.

Prolonged exposure of MSG for 24-72h during early embryonic development activated mitochondrial apoptotic pathway in the brain detected on day 3 and 6 post-fertilization larvae. Previous studies by others demonstrated similar increase of apoptosis following MSG exposure. Chronic accumulation of MSG induced pyramidal neural loss in cortical organotypic culture (Young et al., 2007) and retinal ganglion cell death (Vorwerk et al., 2000). Twenty hours exposure increased cytotoxicity of $1 \mathrm{mM}$ or $10 \mathrm{mM}$ glutamate on differentiating N1E-115 neuronal cells; morphological changes observed as neuritis retraction and cell shrinkage leading to apoptosis (Schelman et al., 2004). Our data showed that prolonged exposure of MSG during early embryo development at dose $10 \mu \mathrm{g} / \mathrm{mL}(50 \mu \mathrm{M})$ increased brain apoptosis. The glutamate of MSG may cause brain apoptosis and behavior changes through its agonist effects on NMDA receptors (Rizzuto, et al., 2003). NMDA receptors are ionotropic receptors mediating glutamatergic neurotransmission and play a role in several basic functions in the central nervous system, from regulating neurodevelopment and synaptic plasticity, learning and memory formation, 
Nia Kurnianingsih
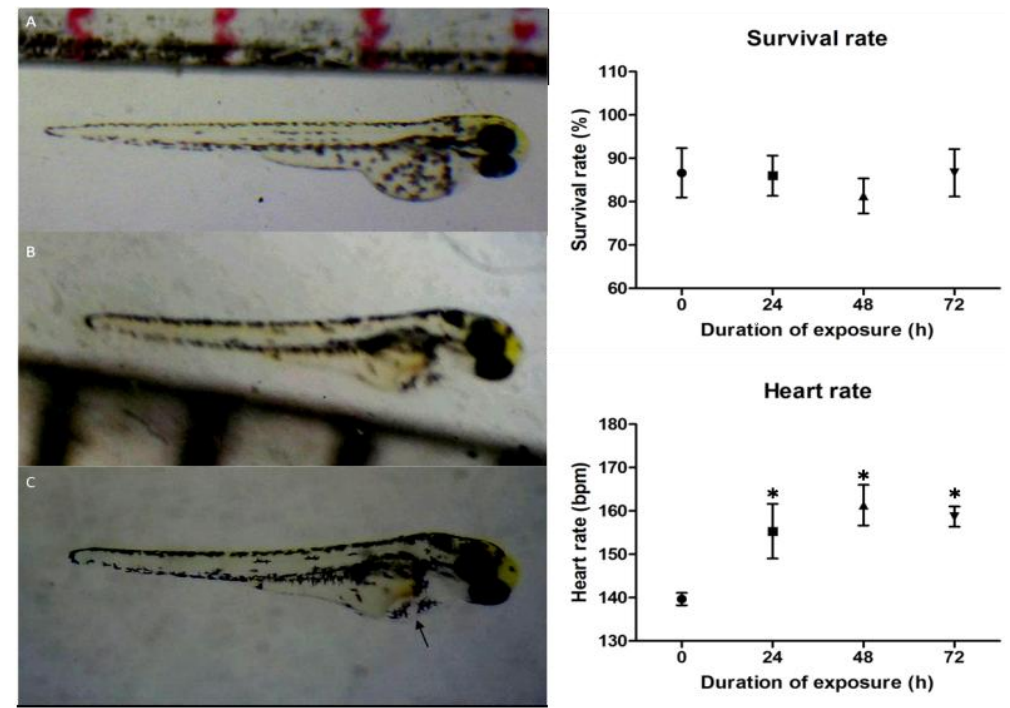

Figure 1. Morphology, survival and heart rate following MSG treatment at early developmental stage. In group treated with MSG for $72 \mathrm{~h}$, there were embryos exhibited shorten body length (B) and cardiac sac edema (C, arrow) which not found in control group (A). Survival rates were not affected with MSG, but heart rate increased significantly $(\mathrm{p}=0,0249)$ compared with that of control untreated $\left(^{*}\right)$.(n=3 embryos/group)

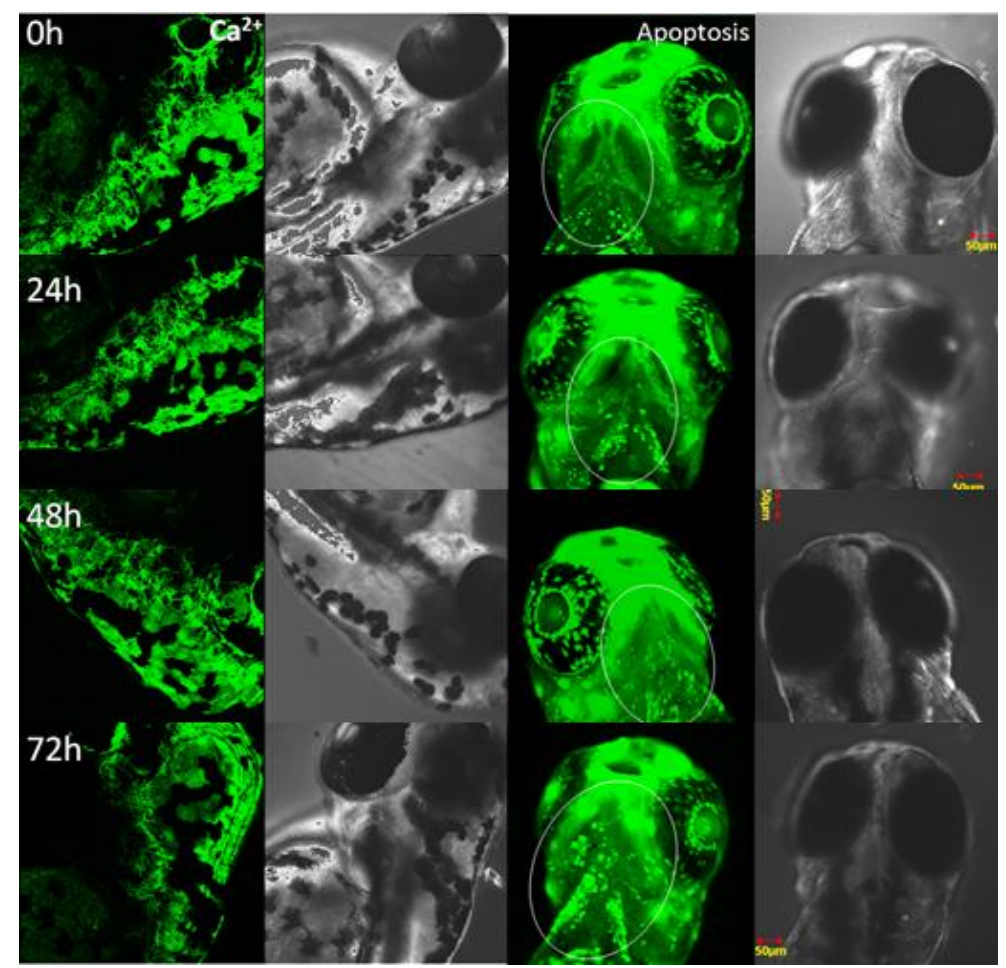

Figure 2. Confocal microscopic observation of calcium and apoptosis embryos treated with MSG. Level of intracellular calcium and apoptosis were observed in embryos 72dpf following MSG treatment for 24; 48; and $72 \mathrm{~h}$ and compared with control untreated (0h). Apoptosis increased in cerebellum (circled area) and other part of brain. Fluorescence images were shown as flatten z-stack images of 40-50 optical slices/embryo ( $n=4$ embryos/group), accompanied with their corresponding bright field images. 

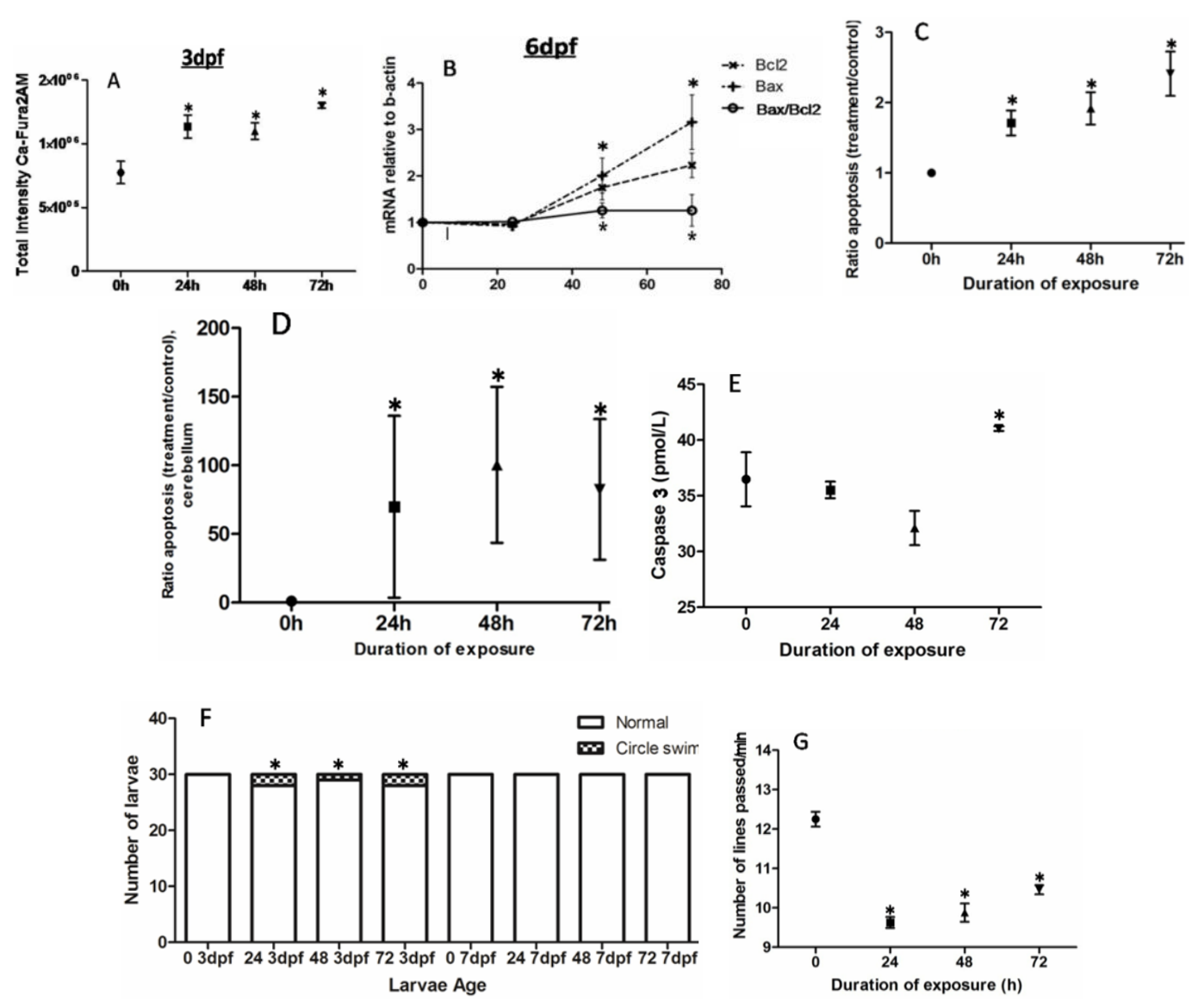

Figure 3. Confocal microscopic observation of calcium and apoptosis embryos treated with MSG. Level of intracellular calcium and apoptosis were observed in embryos 72dpf following MSG treatment for 24; 48; and 72h and compared with control untreated (0h). Apoptosis increased in cerebellum (circled area) and other part of brain. Fluorescence images were shown as flatten z-stack images of 40-50 optical slices/embryo ( $\mathrm{n}=4$ embryos/group), accompanied with their corresponding bright field images.

cognitive processes, rhythm generation necessary for locomotor activity and breathing, and excitotoxicity (Gonda et al., 2012). The longer duration of MSG exposure caused higher accumulation of glutamate in extracellular space of the brain, resulted in overstimulation of NMDA receptor. Next, calcium channel opened, allowing more $\mathrm{Ca}^{2+}$ influxin the cell (Rizzuto et al., 2003). High amount of intracellular $\mathrm{Ca}^{2+}$ led to increased permeability of the mitochondrial membrane, followed by opening of its pores, released cytochrome-c and activated caspase cascade resulted in apoptosis. As evidenced in our study, observed in embryos 3dpf, brain intracellular $\mathrm{Ca}^{2+}$ increased in all groups following MSG treatment (Figure 2-3). Such high amount of intracellular $\mathrm{Ca}^{2+}$ was associated with apoptosis in the brain.

Apoptosis is an important pathogenesis of ASD. Human studies showed that number of Purkinje cells decreased in cerebellum of autistic persons postmortem (Fatemi et al., 2001); the decreasing of number and increasing size of neuronal cells may cause cortex malformation which triggers electric waves resembling epileptic known as epileptiform (Casanova et al., 2013). Glutamate exposure in Zebrafish early embryos causes apoptosis in the brain, the developing nervous system. Apoptosis was highest in group of early embryos treated with $10 \mu \mathrm{g} / \mathrm{mL}$ MSG for $72 \mathrm{~h}$, 
reaching on average for total area of brain 2.5 times and for cerebellum area alone 82 times higher than control group. Cerebellum involves in receiving sensory information and coordination of motoric movement, whereas its cortex is the center of Purkinje cells integrating two circuits of afferent nervous and transmitting stimuli responses into other brain structures (Heap et al., 2013). Therefore, high signal of apoptosis in cerebellum and cortex area may result in disturbance of motoric movement. Indeed, regardless of the duration of MSG exposure, our observation showed that such apoptosis was associated with increased events of circle swims in 3dpf embryos, indicated that MSG increased the risk for stereotypic behavior changes.

Circle swimming is one form of stereotypic behavior, the anxiety-like phenotype, observed in zebrafish as an ASD model (Stewart et al., 2013; Kyzar et al., 2012). Our study showed that prolonged exposure of $10 \mu \mathrm{g} / \mathrm{mL}$ MSG caused circle swimming in $18.33 \%$ of larvae (OR 28.11), whereas the rest $81.67 \%$ remained normal, which means that same MSG exposure did not produce same effect in all larvae. As in ASD ethiopathogenesis may involved both environment and genetics factors (Gentile et al., 2013), the affected zebrafish larvae showing circle swimming may have genetic susceptibility against MSG, which needs further studies to clarify. Many mutations associated with autism have been characterized (Broek et al., 2014), however, which mutation(s) involved in MSG susceptibility causing stereotypic behavior changes are to be identified.

Of note, the circle swimming behavior was not detected in all 7dpf larvae, including those previously showed the behavior on day 3 post-fertilization. Such phenomenon may be explained first, due to the methods of observation, or secondly, by recovery mechanism(s). Firstly, the growth of zebrafish larvae changes fish's body size and shape, swimming movements and the hydrodynamics governing its propulsion (Muller et al., 2004). Larvae $7 \mathrm{dpf}$ are longer than $3 \mathrm{dpf}$ and shows slower circle swim, thus, it is possible that the differences of circle swimming in normal vs MSG treated larvae were too subtle to detect. Secondly, zebrafish larvae possess a mechanism to recover from glutamate toxicity and brain regenerative capability. An in-vitro study showed that increased $\mathrm{Ca}^{2+}$ detected during physiologic glutamate treatment returned to its basal level when glutamate was removed from media (Vaarmann et al., 2013). Similar homeostasis may also be at work during MSG termination in our zebrafish experiments.

In MSG treatment groups, high expression of Bax detected in 6dpf larvae was accompanied with $B c l-2$ increased. As antiapoptosis, $B c l-2$ inhibits apoptosis by forming complex with $B a x$, therefore the ratio of $\mathrm{Bax} / \mathrm{Bcl}-2$ is significant. Ratio of $\mathrm{Bax} / \mathrm{Bcl}-2$ more than 1 will turn the balance of pro/antiapoptosis towards apoptosis, activating caspase signaling (Chan et al., 2007). Bcl-2 is regulated by brain-derived neurothropic factor (BDNF) (Sheikh et al., 2010) which expressed in 24h$7 \mathrm{dpf}$ zebrafish embryo, including in the brain (Felice, et al., 2014). The levels of Bax, Bcl-2, ratio of Bax/Bcl-2 and caspase- 3 of 6dpf larvae were higher in $72 \mathrm{~h}$ MSG treatment than in 24 and $48 \mathrm{~h}$ counterparts. These observed patterns may be associated with the time of recovery of the brain following termination of MSG treatment. On day 6, larvae treated with MSG for 24; 48; and $72 \mathrm{~h}$ had 5; 4; and 3 days, respectively, to recover from MSG brain toxicity.

Zebrafish possesses excitatory amino acid transporter-2 (EAAT2) which removes glutamate from synapses, dissipating glutamate stimulation on NMDA receptor. Zebrafish brain was also capable synthesizing dopamine, known as protectant against toxic effect of glutamate (Vaarmann et al., 2013; Holzschuh et al., 2001). One or all together may operate to reverse condition back to basal, thus, $B a x, B c l-2$, and caspase- 3 decreased, reached normal level in 24h MSG treated embryos, 5 days postcessation of MSG. Our observation suggested that $\mathrm{Bax}, \mathrm{Bcl}-2$ and caspase-3 expressions were associated with MSG treatment. Our results were different from Fukui et al. (Fukui et al., 2009) study which showed that glutamate induced-apoptosis was independent of $B a x, B c l$ 2 and caspases. Such discrepancy may be due to the experimental system used, we studied invivo zebrafish observing the whole brain, whereas Fukui et al. (Fukui et al., 2009) used in vitro hippocampal cells. Another mechanism to 
recover from apoptosis due to excessive glutamate toxicity is that zebrafish may regenerate cells to replace the affected brain cells. Zebrafish hindbrain was demonstrated as highly plastic, facilitated by FGF signaling, able to regenerate and repattern ablated cerebellum, which resulted in no obvious locomotive malfunctions (Koster et al., 2006). Successful cells regeneration and neural network repair will restore the behavior, which may explain the disappearance of circle swimming stereotypic behavior of embryos after MSG exposure ended. Further studies are warranted examining whether such regeneration ensues in all brain area affected by MSG.

In contrast with circle swimming, the locomotor activity observed as number of lines passed per minute decreased significantly in 6dpf larvae in all groups treated with MSG. The locomotor rates were slightly higher in $72 \mathrm{~h}$ MSG treatment than in 24 and $48 \mathrm{~h}$ counterparts. Motor behavior, the locomotion, is generated by specific neural circuits in the spinal cord (Kyriakatos et al., 2011). The motor pattern is mediated by activation of ionotropic glutamate and glycine receptors in the spinal cord. Prolonged NMDA agonist such as MSG may change the shape of the synaptic drive and action potentials in motoneurons. Despite the possibility that NMDA receptor stimulation and apoptosis came to end and brain regeneration ensued when MSG exposure was ended, the recovery of brain cells and functions may not be completed. As the development of brain morphology; neuronal networks; and functions are spatial and temporal-specific, and/or some areas may need longer time to recover, successful in-time repair will restore the behavior, whereas imperfect repair of the affected brain cells may cause associated behavior deviances stay or even worsen with time. In human studies, ASD brain growth is associated with overgrowth at early-age which decelerated during later-age (Courchesne et al., 2001) but with reduced coherence within frontal regions and between frontal and all other regions (Murias et al., 2007). Similar scenario may operate in zebrafish following MSG-treatment-termination during earlyembryo development, resulted in partial recovery. Thus, larvae remained with decreased locomotor activity as shown in this study.
This study showed that prolonged exposure of MSG, $10 \mu \mathrm{g} / \mathrm{mL}$, started on day 1 post-fertilization for 24-72h, increases significantly intracellular calcium and brain apoptosis. Such apoptosis increase the risk and was associated with behavioral changes i.e. increase of circle swim events upon stimuli observed on day 3. Following termination of MSG, some of normal behavior aspects i.e. the circle swimming of $7 \mathrm{dpf}$, but not locomotor activity of $6 \mathrm{dpf}$ larvae, may recover. Further study are required to clarify such recovery which probably through brain detoxification of glutamate and cells regeneration. Conclusion, MSG exposure at early embryonic stage increased brain cell damage and risk of behavior changes.

\section{ACKNOWLEDGMENTS}

This study was supported by funding from the Research and Education Fund via Research Development Institute, Faculty of Medicine, Brawijaya University year 2014 (No.contract 37/SK/UN10.7/UPP/2014) (to $\mathrm{NK}$ and JPU) and Indonesian Scholarship Endowment year 2013 (No.contract: 00017531/BL/M/8/LPDP2013) (to JPU) (provided by Indonesian Government via Ministry of Finance.

\section{REFERENCES}

Abdelkader, T. S., Seo-Na , C., Tae-Hyun, K.,Juha, S.,Dongso, K., and Park, J.,2012. Teratogenicity and Brain Aromatase-induction of Monosodium Glutamate in Estrogen-Responsive Mosaic Transgenic ZebraFish Danio rerio. Afr J Biotech, 11 : 10816-10823.

Abdelkader, T. S., Seo-Na , C., Tae-Hyun, K., Juha, S.,Dongso, K., and Park, J., 2013. Exposure time to caffeine affects heartbeat and cell damage-related gene expression of Zebrafish Danio rerio embryos at early developmental stages. Jo App Tox,33: 1277-1283.

Ali, M. M., Bawari, M., Misra, U. K. and Babu, G. N., 2000. Locomotor and Learning Deficits in Adult Rats Exposed to Monosodium-L-Glutamate during Early Life. Neuroscience Letters, 284:57-60.

American Psychiatric Association., 2013. Diagnostic and Statistical Manual of 
Mental Disorders. $5^{\text {th }}$ ed.American Psychiatric Association, Arlington.USA

Baio, J., 2014. Prevalence of Autism Spectrum Disorder Among Children Aged 8 Years Autism and Developmental Disabilities monitoring Network, 11 Sites, United States, 2010. Morbidity and Mortality Weekly Report,63:1-24.

Beyreuther, K., Biesalski, H.K., Fernstrom, J.D., Grimm,P., Hammes, W.P., Heinemann, U., Kempski,O., Stehle,P., Steinhart, H ., and Walker, R.,2007. Consensus Meeting: Monosodium Glutamate - An Update. Eur J Clin Nutrition,61: 304-313.

Broek J.A., Brombacher, E., Stelzhammer, V., Guest, P.C., Rahmoune, H., and Bahn,S.,2014. The need for a comprehensive molecular characterization of autism spectrum disorders. Int J Neuropsychopharmacol, 17: 651-673.

Casanova, M. F. and Pickett, J., 2013. in Imaging the Brain in Autism (eds Manuel F. Casanova, Ayman S. El-Baz, \& Jasjit S. Suri) Ch. 2, 27-44.

Chan, W. H., Wu, H. J. and Shiao, N. H.,2007.

Apoptotic signaling in methylglyoxaltreated human osteoblasts involves oxidative stress, c-Jun N-terminal kinase,caspase-3, nd p21-activated inase 2. J Cell Biochem, 100:1056- 1069.

Courchesne ,E.,Karns, C.M., Davis, H.R., Ziccardi, R., Carper, R.A., Tigue, Z.D., Chisum, H.J., Moses, P., Pierce, K., Lord, C., Lincoln, A.J., Pizzo, S., Schreibman, L., Haas, R.H., Akshoomoff, N.A., andCourchesne, .Y.,2001. Unusual brain growth patterns in early life in patients with autistic disorder: an MRI study. Neurology, 57:245-254.

Fatemi, S. H. and Halt, A. R.2001. Altered levels of $\mathrm{Bcl}-2$ and p53 proteins in parietal cortex reflect deranged apoptotic regulation in autism. Synapse, 42:281-284.

Fatemi, S.H., Aldinger, K.A., Ashwood , P., Bauman, M.L., Blaha, C.D., Blatt, G.J., Chauhan, A., Chauhan, V., Dager, S.R., et al., 2012. Consensus Paper: Pathological Role of the Cerebellum in Autism. Cerebellum, 11:777-807.
Fukui, M., Song, J. H., Choi, J., Choi, H. J. and Zhu, B. T.,2009. Mechanism of glutamate induced neurotoxicity in HT22 mouse hippocampal cells. Eur J Pharmacol,617: 1-11.

Geha, R.S., Beiser, A., Ren, C., Patterson, R., Greenberger, P.A., Grammer, L.C., Ditto, A.M., Harris, K.E., Shaughnessy, M.A., Yarnold, P.R., Corren, J., and Saxon, A.,2000.Multicenter, doubleblind, placebo-controlled, multiplechallenge evaluation of reported reactions to monosodium glutamate. $J$ Allergy Clin Immunol.,106(5):973-80.

Gentile, I., Zappulo, E., Militerni, R., Pascotto, A., Borgia, G., andBravaccio, C.,2013. Etiopathogenesis of autism spectrum disorders: Fitting the pieces of the puzzle together. Medical Hypotheses, 81:26-35.

Gonda, X., 2012. Basic pharmacology of NMDA receptors. Curr Pharm Des, 18:1558 1567.

Gonzales-Burgos, I., Perez-Vega, M. I. and Beas-Zarate, C.,2001. Neonatal Exposure to Monosodium Glutamate Induces Cell-Death and Dendritic Hypotrophy in Rat Prefrontocortical Pyramidal Neurons. Neuroscience Letters, 297:69-72.

Guo, S., 2004. Linking Genes to Brain, Behaviour and Neurological Disease: What Can We Learn from Zebrafish? Genes, Brain and Behavior,3:63-74.

Felice, E.,D., Porreca, I., Aleva, E., Girolamo, P.D., Ambrosino, C., Ciricao, E., German, A., and Sordino, P.2014.Localization of BDNF expression in the developing brain of zebrafish. J. Anat, 224:564--574

Heap, L., Goh, C.-C., Kassahn, K. S. and Scott, E. K.,2013. Cerebellar output in zebrafish: an analysis of spatial patterns and topography in eurydendroid cell projections. Frontiers in Neural Circuits, 7.

Holzschuh, J., Ryu, S., Aberger, F. and Driever, W.,2001. Dopamine transporter expression distinguishes dopaminergic neurons from other catecholaminergic neurons in the developing zebrafish embryo. Mech Dev, 101:237-243 .

Husarova, V. and Ostatnikova, D.,2013. Monosodium Glutamate Toxic Effects 
and Their Implications for Human Intake: A Review. JMED Research.

Ingebretson, J. J. and Masino, M. A.,2013 Quantification of Locomotor Activity in Larval Zebrafish: Considerations for the Design of High-Throughput Behavioral Studies. Frontiers in Neural Circuits, 7: 109.

Jones, K. L., Will, M. J., Hecht, P. M., Parker, C. L. \& Beversdorf, D. Q.,2013. Maternal diet rich in omega-6 polyunsaturated fatty acids during gestation and lactation produces autisticlike sociability deficits in adult offspring. Behav Brain Res,238: 193-199.

Koster, R. W. \& Fraser, S. E. 2006.FGF signaling mediates regeneration of the differentiating cerebellum through repatterning of the anterior hindbrain and reinitiation of neuronal migration. $J$ Neurosci,26: 7293-7304,

Kyriakatos, A.,Mahmood, R., Ausborn, J., Porres, C.P., Büschge, A., and El Manira, A., 2011.Initiation of locomotion in adult zebrafish. J Neurosci,31:8422-8431.

Kyzar, E.J., Collins, C., Gaikwad, S., Green, J., Roth, A., Monnig, L., El-Ounsi, M., Davis, A., Freeman, A., Capezio, N., Stewart, A.M., and Kalueff, A.V.,2012. Effects of hallucinogenic agents mescaline and phencyclidine on zebrafish behavior and physiology. Prog Neuropsychopharmacol Biol Psychiatry, 37: 194-202.

Mattson, M. P.,2008. Glutamate and Neurotrophic Factors in Neuronal Pasticity and Disease. Annals of the New York Academy of Sciences, 1144:97-112.

McCurley, A. T. \& Callard, G. V., 2008. Characterization of housekeeping genes in zebrafish: male-female differences and effects of tissue type, developmental stage and chemical treatment. BMC Mol Biol,9: 102.

Muller, U. K. \& van Leeuwen, J. L.,2004. Swimming of larval zebrafish: ontogeny of body waves and implications for locomotory development. J Exp Biol,207: 853-868

Muntean,B.S., Horvat, C.M., Behler, J.H., Aboualaiwi, W.A., Nauli, A.M., Williams, F.E., and Nauli, S.M.,2010.A Comparative Study of Embedded and
Anesthetized Zebrafish in vivo on Myocardiac Calcium Oscillation and Heart Muscle Contraction. Frontiers in Pharmacology, 1, 139.

Murias, M., Webb, S. J., Greenson, J. \& Dawson, G.,2007. Resting state cortical connectivity reflected in EEG coherence in individuals with autism. Biol Psychiatry, 62: 270-273,

Parng, C., Ton, C., Lin, Y.-X., Roy, N. M. \& McGrath, P. A.,2006. Zebrafish Assay for Identifying Neuroprotectants in vivo.Neurotoxicology and Teratology,28: 509516.

Pramulawati, D. A., Aurora, H. \& Lyrawati, D.,2014.The Effects of Exposure Time of Zebrafish Cardiac Formation. Jurnal Kedokteran Brawijaya,28: 22-25.

Rizzuto, R., Pinton, P., Ferrari, D., Chami, M., Szabadkai, G., Magalhães, P.J., Di, Virgilio F., and Pozzan, T.,2003. Calcium and Apoptosis: Facts and Hypotheses. Oncogene, 22: 8619- 8627.

Rizzuto, Rosario., et al. 2003.Calcium and apoptosis: facts and hypotheses. Oncogene. 22 : 8619-862

Roberts, J. L., Hovanes, K., Dasouki, M., Manzardo, A. M. \& Butler, M. G.,2014. Chromosomal microarray analysis of consecutive individuals with autism spectrum disorders or learning disability presenting for genetic services. Gene, 535: 70-78.

Schelman, W. R., Andres, R. D., Sipe, K. J., Kang, E. \& Weyhenmeyer, J. A.,2004. Glutamate mediates cell death and increases the $\mathrm{Bax}$ to $\mathrm{Bcl}-2$ ratio in a differentiated neuronal cell line. Molecular Brain Research, 128: 160-169.

Sheikh, A.M., Malik, M., Wen, G., Chauhan, A., Chauhan, V., Gong, CX., Liu, F., Brown, WT., and Li, X.,2010. BDNFAkt-Bcl-2 antiapoptotic signaling pathway is compromised in the brain of autistic subjects. I Neurosci Res, 88:2641-2647.

Siniscalco ,D., Sapone, A., Giordano, C., Cirillo, A., de Novellis, V., de Magistris, L., Rossi, F., Fasano, A., Maione, S., and Antonucci, N.,2012. The expression of caspases is enhanced in peripheral blood mononuclear cells of 
autism spectrum disorder patients. $J$ Autism Dev Disord, 42: 1403-1410.

Stewart, A., Wu, N., Cachat, J., Hart, P., Gaikwad, S., Wong, K., Utterback, E., Gilder, T., Kyzar, E., Newman, A., Carlos, D.,et al., 2011.Pharmacological modulation of anxiety-like phenotypes in adult zebrafish behavioral models. Prog Neuropsychopharmacol Biol Psychiatry,35: 1421-1431.

Stewart, A. M., Nguyen, M., Wong, K., Poudel, M. K. \& Kalueff, A. V., 2014.Developing Zebrafish Models of Autism Spectrum Disorder (ASD). Progress in Neuro Psychopharmacology \& Biological Psychiatry, 50: 27-36,

Tiedeken, J. A., Ramsdell, J. S. \& Ramsdell, A. F.2005.Developmental toxicity of domoic acid in zebrafish (Danio rerio). Neurotoxicol Teratol,27: 711-717.

Vaarmann, A., Kovac, S., Holmstrom, K. M., Gandhi, S. \& Abramov, A. Y., 2013.Dopamine protects neurons against glutamate-induced excitotoxicity. Cell Death Dis,4: e455.

Vargas, R., Johannesdottir, I. T., Sigurgeirsson, B., Thorsteinsson, H. \& Karlsson, K. A.,2011.The Zebrafish Brain in Research and Teaching: A Simple In Vivo and In Vitro Model for the study of spontaneous Neural Activity. Advances in Physiology Education,35: 188-196,

Vorwerk, C.K, Naskar. R., Schuettauf, F., Quinto, K., Zurakowski, D., Gochenauer, G., Robinson, M.B., Mackler, S.A., and Dreyer, E.B. 2000.Depression of retinal glutamate transporter function leads to elevated intravitreal glutamate levels and ganglion cell death. Investigative ophthalmology \& visual science, 41: 3615-3621.

Walker, R. \& Lupien, J. R.,2000.The Safety Evaluation of Monosodium Glutamate. Journal of Nutrition,130: 1049S-1052S.

Westerfield, M.,2000.The Zebrafish Book. A Guide for the Laboratory Use of Zebrafish (Danio rerio). 4 edn, University of Oregon Press.

Young, K.C., McGehee, Daniel and Brorson, J. R.2007. Glutamate receptor expression and chronic glutamate toxicity in rat motor cortex. Neurobiol Dis., 26(1): 7885.

Zhang, Y., Yu, L., Ma, R., Zhang, X., and Yu, T.2010.Comparison of the effects of perinatal and neonatal administration of sodium ferulate on repair following excitotoxic neuronal damages induced by maternal oral administration of monosodium glutamate at a late stage of pregnancy. World Journal of Neuroscience, 2: 159-162 